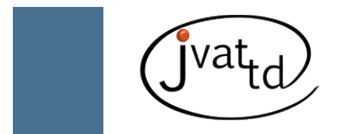

\title{
Inflammatory response, parasite load and AgNOR expression in ear skin of symptomatic and asymptomatic Leishmania (Leishmania) chagasi infected dogs
}

\begin{abstract}
Verçosa BLA (1), Borges ACJ (1), Mendes FJM (2), Costa MLS (2), Pereira NB (1), Melo MN (3), Mendonça IL (4), Costa FAL (4), Vasconcelos AC (1)

(1) Department of General Pathology, Center of Biological Sciences, Federal University of Minas Gerais, Belo Horizonte, Minas Gerais State, Brazil; (2) Zoonosis Control Center, Timon, Maranhão State, Brazil; (3) Department of Parasitology, Center of Biological Sciences, Federal University of Minas Gerais, Belo Horizonte, Minas Gerais State, Brazil; (4) Department of Clinical Veterinary Medicine and Surgery, Center of Agrarian Sciences, Federal University of Piauí, Teresina, Piauí State, Brazil.
\end{abstract}

\begin{abstract}
The skin has an important role in the transmission of visceral leishmaniasis (VL) as the infection pathway in dogs. To better characterize the inflammatory response of intact skin in $V L$, sixty infected dogs (30 symptomatic and 30 asymptomatic) and six non-infected controls were studied. Diagnosis of visceral leishmaniasis was confirmed by RIFI and ELISA; direct visualization of the parasite in bone marrow aspirate; imprints of popliteal lymph nodes, spleen, liver and skin; culture in NNN-phase liquid Schneider's medium; and PCR (performed only in the ear skin). Amastigote forms of the parasite in intact skin were found only in symptomatic dogs. Inflammatory infiltrates were observed in all groups, varying from intense and/or moderate in symptomatic to discrete and/or negligible in asymptomatic and control animals. Parasite load was associated with the intensity of the inflammatory response and with clinical manifestations in canine visceral leishmaniasis. AgNOr as active transcription markers were expressed in inflammatory cells and within apoptotic bodies in all groups, including controls, with no statistical difference. Therefore, cell activation and transcription do occur in both symptomatic and asymptomatic canine visceral leishmaniasis and may result in more necrosis and inflammation or in apoptosis and less symptoms, depending on the parasite load.
\end{abstract}

Key words: visceral leishmaniasis, inflammation, parasites, Leishmania chagasi.

\section{INTRODUCTION}

Visceral leishmaniasis (VL), an endemic zoonosis, is caused by the parasite Leishmania (Leishmania) chagasi, which is transmitted by bites of Lutzomyia longipalpis sand flies $(1,2)$. Clinically, the infection may be asymptomatic, oligosymptomatic (with nonspecific signs of infection) or symptomatic with manifestations including keratitis, onychogryphosis and evident splenomegaly (3).

During its life cycle, Leishmania multiply within cells of the mononuclear phagocytic system of infected humans and dogs (4-6). The vector, a sand fly, bites an affected animal and the amastigote forms of the parasite turn into promastigotes in the gut of the invertebrate host. Transmission occurs during the blood meal of an infected vector, which inoculates promastigotes into the skin of the vertebrate host. Promastigotes engulfed by macrophages are transformed into amastigotes that proliferate and spread, triggering the disease and immunosuppression (7).

Dogs comprise the most important domestic reservoir of visceral leishmaniasis because they show intense cutaneous parasitism, which allows an easy infection of the sand fly $(1,8$, 9). The indiscriminate killing of infected dogs has not diminished the incidence of the disease in endemic areas, probably due to the presence of other infected synanthropic animals or due to a likely human to human transmission (10- 
16). Parasitism in skin does not occur at the same intensity in all stages of the infection and xenodiagnosis has pointed out that a higher percentage of infected vectors is observed only when sand flies feed on symptomatic dogs in advanced stages of the disease (17). The parasite load and severity of skin lesions in symptomatic animals differ significantly from those observed in asymptomatic animals (6). Thus, the intensity of the parasite load and severity of the skin lesions seems to reflect the immune status of the host (18).

Argyrophilic nucleolar organizer regions (AgNORs) are nuclear proteins involved in active transcription during interphase and mitosis. They are good markers for cell activation and/ or proliferation and may be detected by silver staining. Under light microscopy, AgNORs appear as well defined black brownish clusters, from 0.5 to $1.0 \mu \mathrm{m}$ in diameter, with variable number and forms, primarily in and around the nucleolus. Each black dot corresponds, at the ultra-structural level, to the fibrillar center and dense fibrillar component adjacent to the nucleolus and can be considered as a transcriptionally active unit (19).

In this context, the objective of this study was to evaluate the active transcription by AgNORs expression within the inflammatory infiltrates and correlate these findings with the intensity of the inflammatory response, the parasite load and clinical manifestations in dogs naturally infected with Leishmania (Leishmania) chagasi.

\section{MATERIAL AND METHODS}

\section{Animals}

Sixty naturally infected dogs that had tested positive for serological and parasitological tests for VL were divided into two groups: symptomatic $(\mathrm{n}=30)$ - that showed at least one classic clinical manifestation of the disease (except skin involvement), and asymptomatic (n $=30$ ), according to the method proposed by Pozio et al. (3). Six animals were used as non-infected controls, selected from an initial group of 12 . They varied in breed, weight, age and gender. All dogs were from the Zoonosis Control Center of Timon, in the State of Maranhão, Brazil. Efforts were made to avoid unnecessary distress to the animals. Housing, anesthesia and euthanasia concurred with the guidelines established by the Ethics Committee in Animal Experimentation of the Federal University of Minas Gerais that also reviewed and approved this work (UFMGCETEA, process number 198/2007, approved in March 27, 2008).

\section{Diagnosis of Visceral Leishmaniasis}

Diagnosis of visceral leishmaniasis was confirmed by the detection of anti-Leishmania antibodies in sera by indirectimmunofluorescence assay and enzyme-linked immunosorbent assay. After clinical examination, sternal bone marrow aspirates and imprints of popliteal lymph nodes, spleen, liver and skin were fixed, stained with Giemsa, and examined for direct visualization of the parasite (20). Aspirates from the spleen, liver, bone marrow and lymph nodes were also cultured for promastigotes in NNN-phase liquid Schneider's medium. Polymerase chain reaction was performed to detect parasites' nucleic acids in the ear skin, using a target DNA sequence of the Leishmania donovani complex. Animals regarded as non-infected controls presented negative results in all tests, including PCR.

\section{Collection and Processing of Ear Skin Samples}

The animals were anesthetized and fragments of ear skin were harvested for histology and immunohistochemistry. The fragments were processed routinely and stained with HE, Shorr's Trichrome (for conjunctive tissue), GiemsaLemnert (for Leishmania and mast cells), silver impregnation was also used (for AgNOR) whereas Goodpasture's stain and Grocott's stain were employed to rule out bacterial or fungal infection, respectively (21).

Immunohistochemistry for the Detection of Amastigotes of Leishmania (L.) chagasi in the Skin, Liver, Popliteal Lymph Nodes and Spleen

Hyperimmune serum of dogs naturally infected with Leishmania (L.) chagasi was used as a primary antibody for the detection of amastigotes. The reaction was then amplified with LSAB $^{\varpi}$ System-HRP (Biotinylated Link for Streptavidin HRP, cat. K0675, DAKO Corporation, USA) and revealed with a solution of 3, 3'-diaminobenzidine (DAB, Sigma Chemical, USA). Slides with skin sections were incubated with hyperimmune serum of infected dog and PBS only, as positive and negative controls, respectively (22). 
Analysis of Cell Activation and Transcription - AgNORs

Cell activation and transcription was evaluated through the quantification of AgNORs in 100 nuclei of inflammatory cells per animal, within the inflammatory foci, according to Crocker et al. (19). The total number was divided by 100 to obtain the mean of AgNORs per animal.

\section{Polymerase Chain Reaction (PCR) in Ear Skin Fragments}

DNA was extracted from samples of all animals with a genomic DNA tissue kit (NucleoSpin ${ }^{\circledR}$ Tissue, Macherey-Nagel, Germany). The polymerase chain reaction was performed with the GoTaq ${ }^{\circledR}$ Green Master Mix kit (Promega Corporation, cat. M7122, USA). L. donovani complex-specific sequence was used as described by Piarroux et al. (23). DNA from an embedded paraffin skin sample of dogs naturally infected with Leishmania (L.) chagasi (with intense cutaneous parasite load) and DNA of Leishmania (L) chagasi culture (strain MHOM/BR/BH46) were used as positive controls. Skin DNA of a confirmed non-infected dog and a solution with all reaction components (master mix), except DNA, were used as negative controls. The DNA amplification protocol was described by Laskay et al. (24). PCR amplicons were analyzed in polyacrylamide gel electrophoresis in 5\% nondenaturing TBE (89 mM Tris-borate, $2 \mathrm{mM}$ EDTA pH 8.0). Subsequently, the gels were fixed and photographed with a digital camera.

\section{Descriptive Evaluation of the Parasite Load and Inflammatory Response of the Skin}

Intensity, composition and distribution of the inflammatory response and parasite load in ear skin were evaluated on Shorr stained sections and immunohistochemistry. Inflammatory infiltrates were classified, as described by Solano-Gallego et al. (25), into discrete and focal, moderate and multifocal, and severe and diffuse. The parasite load and intensity of the inflammatory infiltrate were graded according to Verçosa et al. (6) as follows: 0 - absent, 1 - minimal, 2 - mild and 3 - severe.

\section{Statistical Analysis}

Data collection and statistical tests were performed using blind analysis (26). Data were analyzed by nonparametric Kruskal-Wallis test and Dunn post-test for multiple comparisons. The chi-square was also employed to test the association of variables.

\section{RESULTS}

The main clinical manifestations of symptomatic animals with intact skin were: lymphadenopathy (23 cases; $76.7 \%)$, conjunctivitis (12 cases; 40.0\%), splenomegaly (8 cases; $26.7 \%$ ) and onychogryphosis (8 cases; $26.7 \%)$, as displayed in Table 1 . All other clinical manifestations of VL were less frequent than $10 \%$.

Initially, 12 dogs were assigned into the control group (with negative results on serological and parasitological tests), but two of them presented positive results in PCR, other two animals presented at least one clinical sign of VL (lymphadenopathy and/or conjunctivitis, despite the negative result in serological and parasitological tests) and two others had bacterial and/or fungal skin infections. All these animals were excluded from the samples analyzed in this study, remaining six animals as controls. Anti-Leishmania antibodies were detected in all infected animals, with titers ranging from 1:40 through 1:640. All symptomatic and asymptomatic animals were positive in at least three of the four parasitological tests (Giemsa, culture, PCR and immunohistochemistry) in different organs, according to Table 2.

Both infected and control animals showed inflammatory infiltrates in ear skin. The intensity of inflammation was directly associated with clinical manifestations and parasite load ( $p$ $<0.01$, chi-square test). Thus, more intense inflammation and a higher parasite load were found in the symptomatic group (Figure 1, p < 0.05, Kruskal Wallis and Dunn).

Fourteen out of 30 symptomatic animals showed moderate and multifocal inflammatory infiltrates, located around hair follicles, sebaceous glands and blood vessels (Figure $2-A$ ). Infiltrates were classified as discrete and focal occurring in the subepidermal region and rarely deep in the dermis in 11 of the 30 symptomatic dogs. Severe and diffuse inflammatory infiltrates were observed in only five of the 30 symptomatic animals. Macrophages were the predominant cells, besides lymphocytes and plasma cells. Neutrophils were seen in the dermis in seven out of 30 symptomatic animals (Figure $2-$ B). Only one symptomatic 
Table 1. Association among inflammatory infiltrate, parasite load and clinical signs in canine leishmaniasis $(n=30)$

\begin{tabular}{|c|c|c|c|c|c|c|c|}
\hline \multirow{2}{*}{ Dogs } & \multicolumn{4}{|c|}{ Clinical manifestations } & \multirow{2}{*}{$\begin{array}{c}\begin{array}{c}\text { Inflammatory } \\
\text { infiltrate* }\end{array} \\
\begin{array}{c}\text { Shorr's tri- } \\
\text { chrome }\end{array}\end{array}$} & \multirow{2}{*}{$\begin{array}{c}\text { Parasite load" } \\
\begin{array}{c}\text { Immunohistochem- } \\
\text { istry }\end{array}\end{array}$} & \multirow{2}{*}{$\mathrm{PCR}^{\sharp}$} \\
\hline & $\begin{array}{l}\text { Lymphade- } \\
\text { nopathy }\end{array}$ & $\begin{array}{l}\text { Conjunc- } \\
\text { tivitis }\end{array}$ & $\begin{array}{l}\text { Spleno- } \\
\text { megaly }\end{array}$ & $\begin{array}{l}\text { Onycho- } \\
\text { phosis }\end{array}$ & & & \\
\hline 01 & + & + & + & - & 2 & 1 & + \\
\hline 02 & + & + & - & - & 1 & 1 & + \\
\hline 03 & + & - & + & - & 1 & 0 & + \\
\hline 04 & - & + & - & + & 2 & 1 & + \\
\hline 05 & + & + & - & - & 2 & 1 & + \\
\hline 06 & + & - & - & - & 1 & 0 & + \\
\hline 07 & + & + & + & + & 2 & 1 & + \\
\hline 08 & + & + & - & - & 2 & 0 & + \\
\hline 09 & - & - & - & + & 3 & 2 & + \\
\hline 10 & + & - & - & + & 1 & 0 & + \\
\hline 11 & + & - & - & - & 1 & 0 & + \\
\hline 12 & + & + & - & - & 2 & 2 & + \\
\hline 13 & - & - & + & - & 2 & 1 & + \\
\hline 14 & + & - & - & - & 3 & 2 & + \\
\hline 15 & - & - & + & - & 1 & 0 & + \\
\hline 16 & + & - & - & - & 1 & 0 & - \\
\hline 17 & + & - & + & - & 2 & 1 & + \\
\hline 18 & + & - & + & - & 1 & 0 & + \\
\hline 19 & - & - & - & + & 1 & 0 & + \\
\hline 20 & + & + & - & - & 3 & 3 & + \\
\hline 21 & + & - & - & - & 3 & 2 & + \\
\hline 22 & + & + & - & + & 1 & 0 & + \\
\hline 23 & + & - & + & - & 2 & 1 & + \\
\hline 24 & - & + & - & - & 1 & 0 & - \\
\hline 25 & - & + & - & + & 3 & 3 & + \\
\hline 26 & + & - & - & - & 1 & 0 & + \\
\hline 27 & + & - & - & - & 2 & 2 & + \\
\hline 28 & + & + & - & + & 2 & 1 & + \\
\hline 29 & + & - & - & - & 1 & 0 & + \\
\hline 30 & + & - & - & - & 1 & 0 & + \\
\hline
\end{tabular}

*,\# For grading method, see "Materials and Methods". 
Table 2. Parasitological tests (Giemsa, culture, PCR and immunohistochemistry) performed in different organ samples according to clinical status of dogs naturally infected with Leishmania (L.) chagasi $(\mathrm{n}=60)$

\begin{tabular}{|c|c|c|c|c|c|c|c|c|c|c|c|c|c|c|c|}
\hline \multirow{3}{*}{ Dogs } & \multirow{3}{*}{$\begin{array}{l}\text { Clini- } \\
\text { cal } \\
\text { status }\end{array}$} & \multicolumn{14}{|c|}{ Parasitological tests } \\
\hline & & \multicolumn{3}{|c|}{ Liver } & \multicolumn{3}{|c|}{ Popliteal lymph node } & \multicolumn{3}{|c|}{ Spleen } & \multicolumn{2}{|c|}{ Bone marrow } & \multicolumn{3}{|c|}{ Skin } \\
\hline & & $\begin{array}{c}\text { Gi- } \\
\text { emsa }\end{array}$ & $\begin{array}{l}\text { Cul- } \\
\text { ture }\end{array}$ & IHC & $\begin{array}{c}\text { Gi- } \\
\text { emsa }\end{array}$ & $\begin{array}{l}\text { Cul- } \\
\text { ture }\end{array}$ & IHC & $\begin{array}{c}\text { Gi- } \\
\text { emsa }\end{array}$ & $\begin{array}{l}\text { Cul- } \\
\text { ture }\end{array}$ & IHC & $\begin{array}{c}\text { Gi- } \\
\text { emsa }\end{array}$ & $\begin{array}{l}\text { Cul- } \\
\text { ture }\end{array}$ & $\begin{array}{l}\text { Gi- } \\
\text { emsa }\end{array}$ & PCR & $\mathrm{IHC}$ \\
\hline 01 & $\mathrm{~S}$ & - & + & + & + & - & + & + & + & + & + & + & + & + & + \\
\hline 02 & $\mathrm{~S}$ & - & + & - & + & - & + & - & + & + & + & + & + & + & + \\
\hline 03 & $\mathrm{~S}$ & - & - & + & + & - & + & - & + & + & + & + & + & + & - \\
\hline 04 & $\mathrm{~S}$ & + & + & - & + & - & + & - & + & + & + & + & + & + & + \\
\hline 05 & $\mathrm{~S}$ & - & - & + & + & - & + & + & + & - & + & + & + & + & + \\
\hline 06 & $\mathrm{~S}$ & - & + & - & + & - & + & + & + & - & + & + & + & + & - \\
\hline 07 & $\mathrm{~S}$ & - & - & + & - & + & + & + & + & - & + & + & + & + & + \\
\hline 08 & $\mathrm{~S}$ & + & - & + & - & + & + & + & + & + & - & + & - & + & - \\
\hline 09 & $\mathrm{~S}$ & + & - & + & + & + & + & + & + & + & - & + & - & + & + \\
\hline 10 & $S$ & + & - & + & + & - & + & + & - & + & - & + & + & + & - \\
\hline 11 & $\mathrm{~S}$ & + & + & + & - & + & + & + & - & + & + & + & + & + & - \\
\hline 12 & $\mathrm{~S}$ & + & + & + & - & + & + & + & - & + & + & + & + & + & + \\
\hline 13 & $S$ & + & + & + & - & + & + & + & - & + & + & + & + & + & + \\
\hline 14 & $\mathrm{~S}$ & + & + & + & + & + & - & + & - & + & + & - & + & + & + \\
\hline 15 & $\mathrm{~S}$ & - & + & + & + & + & - & + & + & - & + & - & + & + & - \\
\hline 16 & $S$ & - & + & + & + & + & + & + & + & - & + & + & + & - & - \\
\hline 17 & $S$ & - & + & + & + & + & + & + & + & - & - & + & + & + & + \\
\hline 18 & $\mathrm{~S}$ & - & - & + & + & - & + & + & + & + & - & + & - & + & - \\
\hline 19 & $\mathrm{~S}$ & + & - & + & + & - & + & + & - & + & - & + & + & + & - \\
\hline 20 & $S$ & + & - & + & + & - & + & + & - & + & - & + & + & + & + \\
\hline 21 & $\mathrm{~S}$ & + & + & - & + & + & + & + & + & + & - & + & + & + & + \\
\hline 22 & $S$ & - & + & + & + & + & + & + & - & + & + & - & + & + & - \\
\hline 23 & $\mathrm{~S}$ & - & + & + & + & + & + & + & - & + & + & - & + & + & + \\
\hline 24 & $\mathrm{~S}$ & - & + & + & + & + & + & + & - & - & + & + & - & - & - \\
\hline 25 & $\mathrm{~S}$ & + & + & + & + & + & + & + & - & - & + & + & + & + & + \\
\hline 26 & $\mathrm{~S}$ & + & + & + & + & + & + & + & - & - & + & + & + & + & - \\
\hline 27 & $\mathrm{~S}$ & + & + & + & + & - & + & - & + & + & + & + & + & + & + \\
\hline 28 & $\mathrm{~S}$ & + & - & - & + & - & + & - & + & + & - & + & + & + & + \\
\hline 29 & $\mathrm{~S}$ & + & - & - & + & + & + & - & + & + & - & + & - & + & - \\
\hline 30 & $S$ & + & - & - & + & + & + & - & + & + & - & + & - & + & - \\
\hline 31 & A & + & + & + & - & + & - & + & - & + & + & - & - & + & - \\
\hline 32 & A & + & + & + & - & + & + & + & + & + & + & - & - & + & - \\
\hline 33 & A & + & + & + & - & + & + & + & + & + & + & + & - & + & - \\
\hline 34 & $A$ & + & + & + & - & + & - & + & + & + & + & + & - & - & - \\
\hline 35 & A & - & + & + & - & + & - & + & + & + & + & + & - & + & - \\
\hline 36 & A & - & + & + & - & + & + & - & + & + & - & + & - & + & - \\
\hline 37 & A & + & + & + & + & + & + & - & + & + & + & + & - & + & - \\
\hline 38 & $\mathrm{~A}$ & - & + & - & + & + & + & - & + & + & + & + & - & + & - \\
\hline 39 & $\mathrm{~A}$ & - & + & + & + & + & + & - & - & + & + & + & - & + & - \\
\hline 40 & A & - & + & + & + & + & + & + & + & + & - & + & - & - & - \\
\hline 41 & $A$ & - & + & + & - & + & + & + & + & + & - & + & - & + & - \\
\hline 42 & A & - & + & + & - & + & + & - & + & + & - & + & - & + & - \\
\hline 43 & $A$ & + & + & + & - & + & + & + & + & - & + & + & - & + & - \\
\hline 44 & A & + & - & + & - & + & + & + & + & - & + & + & - & + & - \\
\hline 45 & A & + & + & + & + & + & + & + & + & + & + & + & - & - & - \\
\hline 46 & A & + & + & - & + & + & - & + & + & + & + & + & - & + & - \\
\hline 47 & $A$ & - & + & - & + & + & - & - & + & + & + & + & - & + & - \\
\hline 48 & A & - & + & - & - & + & - & - & + & + & + & + & - & + & - \\
\hline 49 & A & - & + & - & - & - & + & + & + & + & + & + & - & + & - \\
\hline 50 & A & - & + & - & - & - & + & + & - & + & + & + & - & + & - \\
\hline 51 & A & + & + & + & - & + & + & + & - & + & + & + & - & - & - \\
\hline 52 & A & + & + & + & + & + & + & + & + & + & + & + & - & + & - \\
\hline 53 & A & + & + & + & + & + & + & + & + & - & + & + & - & + & - \\
\hline 54 & A & - & + & + & + & + & + & - & + & + & - & + & - & + & - \\
\hline 55 & A & - & + & + & + & + & + & + & + & + & - & + & - & + & - \\
\hline 56 & $A$ & - & + & + & + & + & + & + & + & + & - & + & - & + & - \\
\hline 57 & A & + & + & + & + & + & + & + & + & + & + & + & - & + & - \\
\hline 58 & A & + & + & + & + & - & + & + & + & + & + & + & - & + & - \\
\hline 59 & $\mathrm{~A}$ & + & + & + & + & - & + & - & + & - & - & + & - & + & - \\
\hline 60 & A & + & + & + & + & - & + & - & + & - & - & + & - & + & - \\
\hline
\end{tabular}

S: symptomatic dog; A: asymptomatic dog; IHC: immunohistochemistry. 


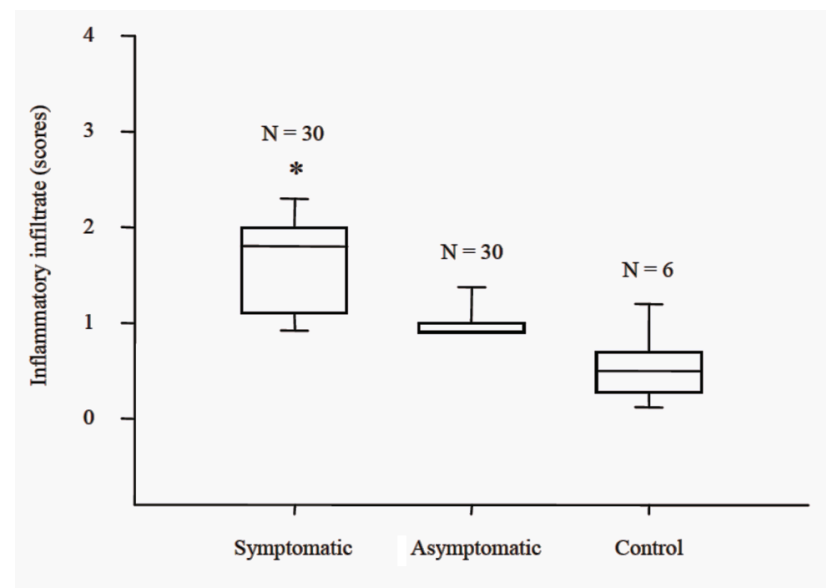

Figure 1. Graph showing inflammatory areas in the ear skin of dogs infected with visceral leishmaniasis. Symptomatic dogs $(n=30)$ presented more inflammation than asymptomatic ones $(n=30)$ and controls $(n=6)$ (Kruskal Wallis and Dunn, $\left.{ }^{*} p<0.05\right)$.

animal had diffuse infiltrates composed mainly of neutrophils and a few macrophages.

Most of the asymptomatic animals (28 of 30) showed discrete and focal inflammation (perifollicular, perivascular and rarely subepidermal), composed predominantly of macrophages, lymphocytes and plasma cells (Figure $2-\mathrm{C}$ ). In these animals, moderate and multifocal infiltrates were observed in only two out of 30. Four of the six non-infected controls had discrete and focal inflammation. In such cases, the inflammatory infiltrate was composed of few lymphocytes, plasma cells and a few macrophages.

Skin biopsies from symptomatic dogs, besides showing more intense inflammatory infiltrate were the only ones that presented parasite load. Sixteen out of 30 symptomatic animals had Leishmania amastigotes in the skin identified by immunohistochemistry (Figure 2 - D). Intense presence of Leishmania parasites was observed only in one dog (Table 1). Six dogs showed moderate infection and in nine of them, the parasite load was graded as discrete to minimal. By contrast, the asymptomatic group had only discrete and/or negligible focal inflammation, and immunohistochemical examination failed to reveal Leishmania amastigotes (Figures $2-\mathrm{E}$ ). The PCR showed that 28 of 30 symptomatic dogs had Leishmania DNA. On the other hand, 26 of 30 asymptomatic dogs showed positive results by PCR.
AgNORs were diffusely expressed in inflammatory cells and within apoptotic bodies in all infected animals (Figure $2-$ F). Symptomatic dogs showed $3.364 \pm 0.3954$ AgNORs per animal. On the other hand, asymptomatic animals and controls expressed $2.978 \pm 0.2567$ and $3.283 \pm$ 0.3883 AgNORs per animal, respectively. There was no statistical difference between groups ( $\mathrm{p}>$ 0.05, Kruskal Wallis and Dunn).

\section{DISCUSSION}

Clinical diagnosis of canine VL in endemic areas is quite difficult because the symptoms may vary and frequently overlap the ones found in other diseases (27-28). The three most frequent clinical manifestations found in this study were lymphadenopathy, conjunctivitis and splenomegaly, which were also observed by Almeida et al. (29). However, two out of 12 animals with negative parasitological and serological tests (candidates to our control group) presented one or more clinical signs of VL and because of that were excluded from the control group. Therefore, clinical diagnosis should not rely on the number of clinical manifestations, since only one or two clinical signs are insufficient to be used as clinical parameters of VL. However, if the three most common clinical signs observed in this study (lymphadenopathy, conjunctivitis and splenomegaly) occur in one animal in an endemic area, it strongly suggests of Leishmania (L.) chagasi infection. Amastigotes were found only in intact ear skin of symptomatic animals. The intensity of parasite load in these animals ranged from minimal to severe. No evidence of Leishmania in asymptomatic dogs was also observed in another study that analyzed ear skin samples of 35 animals, examined by immunohistochemistry and PCR (25). Such results indicate that amastigotes in the skin of infected dogs are frequent only in symptomatic animals. Accordingly, intact skin can be used as a good site to search for parasites in endemic areas and in symptomatic animals, as established in this study $(6,30)$.

Our results indicate that asymptomatic dogs do not appear to harbor parasites in the skin, which corroborates the reports by Verçosa et al. (6), Travi et al. (31) and Guarga et al. (32) that stated that asymptomatic dogs are not able to infect the vector and therefore have low epidemiological 


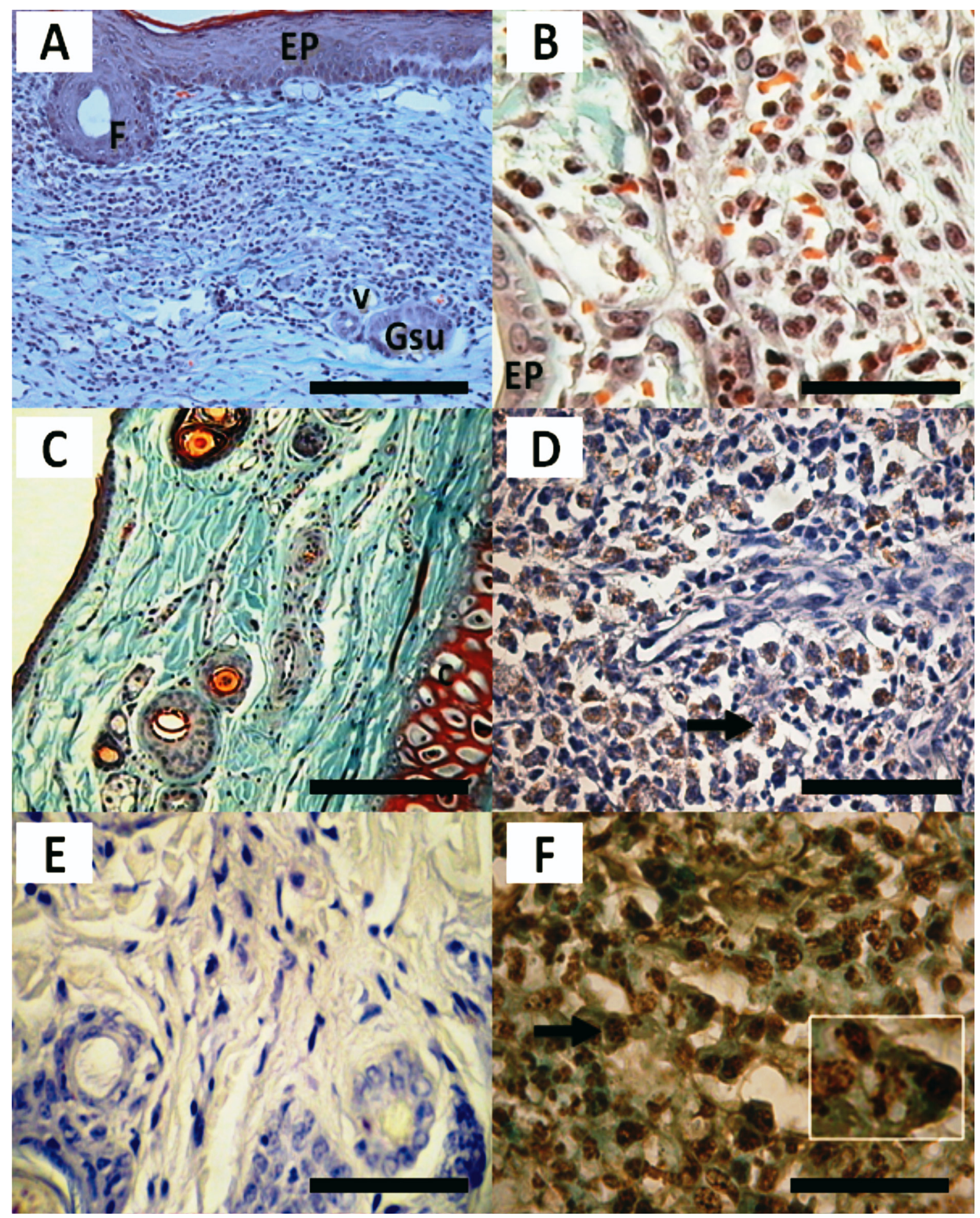

Figure 2. Representative histological sections $(5 \mu \mathrm{m})$ of ear skin samples from dogs affected by canine leishmaniasis. (A) Symptomatic dogs: moderate, multifocal, perivascular, subepidermal and periglandular inflammatory infiltrates. Shorr's trichrome stain. Bar: $100 \mu \mathrm{m}$. (B) Symptomatic dogs: focal and subepidermal inflammatory infiltrates with neutrophils and macrophages. Shorr's trichromic stain. Bar: $25 \mu \mathrm{m}$. (C) Asymptomatic dogs: mild, multifocal perivascular and perifollicular inflammatory infiltrates. Shorr's trichrome stain. Bar: $100 \mu \mathrm{m}$. (D) Symptomatic dogs: amastigotes within macrophages (black arrow), immunohistochemical test for Leishmania chagasi detection. Immunoperoxidase staining. Bar: $25 \mu \mathrm{m}$. (E) Asymptomatic dogs: absence of amastigotes forms of the parasite, immunohistochemical test for Leishmania chagasi detection. Imunoperoxidase staining. Bar: 25 um. (F) Symptomatic dogs: AgNORs within nuclei of inflammatory cells (black arrows, small brown circular or oval structures) and apoptotic bodies (seen in detail below left). AgNOR staining. Bar: 25 mm. EP: keratinized stratified squamous epithelium, F: follicle, V: blood vessel (arteriole), Gsu: sweat gland, C: hyaline cartilage, Gse: sebaceous gland. 
risk. On the other hand, asymptomatic dogs of an endemic area in Spain were capable of transmitting Leishmania infantum (9). These differences may be associated with Leishmania strain and vector species, which are different in Mediterranean region and South America. It is well know that Phlebotomus perniciosus is more efficient than Lutzomyia longipalpis as vector to transmit viscerotropic Leishmania (31).

Inflammation was observed in all groups, even in controls. The ear of dogs is a common target for insect bites, trauma and other parasitic infections (33). That may be an acceptable explanation for the inflammation in the ear skin of controls. Although it was not possible to have a prior knowledge of health and nutritional conditions of the dogs used in this study, one could not rule out previous infections. The present work studied only homeless dogs, captured as part of a program for the control of visceral leishmaniasis and urban rabies. Because we excluded animals presenting macroscopical skin lesions and bacterial/fungal infections, it seems to be acceptable that the inflammatory lesions found in symptomatic and asymptomatic dogs were provoked by Leishmania (L.) chagasi. Moreover, in all infected dogs, leishmaniasis was confirmed by cytological, immunological and molecular approaches. Besides, clinical examination and autopsy showed no evidences of other diseases.

Our results clearly show that Leishmania can induce inflammatory responses in different intensities and patterns in the ear skin of affected dogs. This fact, combined with the absence of amastigotes in asymptomatic dogs, suggests that the animals are immunocompetent and capable of controlling the infection over time as observed in a mouse model infected with Leishmania major (18). The overall results corroborate earlier previous study by Verçosa et al. (6), in which the skin of symptomatic dogs exhibited amastigotes and inflammatory infiltrates, whereas asymptomatic animals had an inflammatory profile similar to non-infected controls.

In this context, the type of inflammatory infiltrate corresponds to the immune response profile against the parasite and the degree of susceptibility of animals to the disease (19). As observed in this study, inflammatory infiltrates in the perifollicular, perivascular and periglandular regions of the skin of resistant hosts (controls and asymptomatic dogs) is composed of lymphocytes, plasma cells and macrophages (6, $25,34-36)$. Whereas inflammatory infiltrates in susceptible individuals (symptomatic dogs) is composed frequently of macrophages containing cytoplasmic vacuoles filled with parasites (37).

Neutrophils were observed only in symptomatic dogs that had increased parasite load associated with intense inflammatory infiltrate. In early infection, neutrophils seem to play a role in controlling the parasite load in the spleen, but not in the liver (38). It has been observed also that dead neutrophils isolated from BALBc mice exacerbated the growth and death of Leishmania (L.) major, respectively (39). Therefore, the role of neutrophils appears to be dependent on the target organ, the time of exposure to infection and the genotype of the individual. Moreover, in vitro infection of neutrophils with Leishmania major protects these cells from apoptosis, which results in intracellular survival of the parasite. Infected neutrophils were then engulfed by activated macrophages, which in advanced stages of infection become resistant to apoptosis, contributing to maintenance of the infection (40). It is likely that ear skin lesions in this study are involved in interactions among neutrophils, macrophages and Leishmania, leading to maintenance and progression of the parasitic infection by mechanisms not well defined yet.

Quantification of nucleolus organizing regions (NOR) as transcription markers to evaluate cell activation could not discriminate symptomatic, asymptomatic and controls in the current study. Although Leishmania (L.) chagasi induces inflammation, it is quite possible that it inhibits cell activation in dogs, which could deregulate the microbicidal mechanism of the host cells and therefore facilitate the parasite survival (41). Besides that, it is likely that cell activation and transcription do occur in both symptomatic and asymptomatic canine visceral leishmaniasis and may result in more necrosis and inflammation or in apoptosis and less symptoms, depending on the parasite load.

In conclusion, there is an association among the parasite load in the skin, inflammatory response and clinical manifestations in dogs naturally infected with Leishmania chagasi. Symptomatic animals presented more intense inflammatory response associated with higher parasite load. Additionally, AgNOR as transcription markers that evaluate cell activation could not differentiate symptomatic and asymptomatic dogs. This 
finding suggests that cell activation may occur in both situations, but with different outputs, resulting in more necrosis and inflammation in symptomatic infection or in apoptosis and less symptoms in asymptomatic infections, depending on the parasite load.

\section{ACKNOWLEDGEMENTS}

Thanks are due The National Council for Scientific and Technological Development (CNPq) and The State of Minas Gerais Research Foundation (FAPEMIG) which financially supported the present study.

\section{COPYRIGHT}

(C) CEVAP 2011

\section{SUBMISSION STATUS}

Received: February 15, 2001.

Accepted: June 13, 2011.

Abstract published online: June 17, 2011.

Full paper published online: August 31, 2011.

\section{CONFLICTS OF INTEREST}

There is no conflict.

\section{FINANCIAL SOURCE}

The National Council for Scientific and Technological Development (CNPq) and The State of Minas Gerais Research Foundation (FAPEMIG) provided the financial grants.

\section{ETHICS COMMITTEE APPROVAL}

The present study was approved by the Ethics Committee in Animal Experimentation of the Federal University of Minas Gerais (UFMGCETEA, process number 198/2007, approved in March 27, 2008).

\section{CORRESPONDENCE TO}

BÁRBARA LAURICE ARAÚJO VERÇOSA, Laboratório de Apoptose, Departamento de Patologia Geral, Instituto de Ciências Biológicas, Universidade Federal de Minas Gerais. Phone: +55 313409 2889. Fax: +55 313409 2878. Email: brbaravet@yahoo.com.br.

\section{REFERENCES}

1. Deane LM, Deane MP. Leishmaniose visceral urbana (no cão e no homem) em Sobral, Ceará. Hospital, Rio de Janeiro. 1955;47(1):75-87.

2. Lanzaro GC, Warburg A. Genetic variability in phlebotomine sandflies: possible implications for leishmaniasis epidemiology. Parasitol Today. 1995;11(4):151-4.

3. Pozio E, Grandoni L, Bettini S, Gramiccia M. Leishmaniasis in Tuscany (Italy): IV. Canine leishmaniasis in the focus of Monte Argentario (Grosseto). Acta Trop. 1981;38(4):383-93.

4. Dutra M, Martinelli R, de Carvalho EM, Rodrigues LE, Brito E, Rocha H. Renal involvement in visceral leishmaniasis. Am J Kidney Dis. 1985;6(1):22-7.

5. Duarte MI, Silva MR, Goto H, Nicodemo EL, Amato Neto V. Interstitial nephritis in human kala-azar. Trans R Soc Trop Med Hyg. 1983;77(4): 531-7.

6. Verçosa BL, Lemos CM, Mendonça IL, Silva SM, de Carvalho SM, Goto $\mathrm{H}$, et al. Transmission potential, skin inflammatory response, and parasitism of symptomatic and asymptomatic dogs with visceral leishmaniasis. BMC Vet Res. 2008;4(1):45.

7. Pinelle E, Killick-Kendrick R, Wagenaar J, Bernadina W, del Real G, Ruitenberg J. Cellular and humoral immune responses in dogs experimentally and naturally infected with Leishmania infantum. Infect Immun. 1994;62(1):229-35.

8. Abranches P, Campino L, Santos-Gomes GM. Leishmaniose visceral canina: novos conceitos de epidemiologia e imunopatologia e seus reflexos no controle da leishmaniose visceral humana. Acta Med Port. 1998;11(10):871-5.

9. Molina R, Amela C, Nieto J, San-Andrés M, Gonzalez F, Castillo JA, et al. Infectivity of dogs naturally infected with Leishmania infantum to colonized Phlebotomus perniciosus. Trans R Soc Trop Med Hyg. 1994; 88(1):491-3.

10. Dietze R, Barros G, Teixeira L, Harris J, Michelson K, Falqueto A, et al. Effect of eliminating seropositive canines on the transmission of visceral leishmaniasis in Brazil. Clin Infect Dis. 1997;25(5):1240-2.

11. Reithinger R, Davies CR. Is the domestic dog (Canis familiaris) a reservoir host of American cutaneous leishmaniasis? A critical review of the currents evidence. Am J Trop Med Hyg. 1999;61(4):530-41.

12. Capelli G, Baldelli R, Ferroglio E, Genchi C, Gradoni L, Gramiccia M, et al. Monitoring of canine leishmaniasis in northern Italy: an update from a scientific network. Parassitologia. 2004;46(1-2):193-7.

13. Bettini S, Grandoni L. Canine leishmaniasis in the Mediterranean area and its implications for human leishmaniasis. Insect Sci Applic. 1986;7(1):241-5.

14. Lainson P. Ecological interactions in the transmission of the leishmaniasis. Phil Trans $\mathrm{R}$ Soc Lond. 1988;B321(1):389-404.

15. Ashford RW. Leishmaniasis reservoirs and their significance in control. Clin Dermatol. 1996;14(5):52332.

16. Costa CH, Gomes RB, Silva MR, Garcez LM, Ramos PK, Santos RS, et al. Competence of the human host as reservoir for Leishmania chagasi. J Infect Dis. 2000;182(3):997-1000.

17. Lainson R, Shaw JJ. Evolution, classification and geographical distribution. In: Peters W, KillickKendrick R, editors. The leishmaniasis in biology and 
medicine. London: Academic Press; 1987. 120 p.

18. Lemos de Sousa V, Ascensão Souza J, Correia Silva TM, Sampaio Tavares Veras P, Rodrigues-de-Freitas LA. Different Leishmania species determine distinct profiles of immune and histopathogical response in CBA mice. Microbes Infect. 2000;2(15):1807-15.

19. Crocker J, Boldy DA, Egan MJ. How should we count AgNORs? Proposals for a standardized approach. J Pathol. 1989;158(3):185-8.

20. Mikel UV. Advanced laboratory methods in histology and pathology. Washington: Armed Forces Institute of Pathology; 1994. 230-2 p.

21. Luna LG. Manual of the histologic staining methods of the Armed Forces Institute of Pathology. 3th ed. New York: Mc Graw-Hill; 1968. 258 p.

22. Tafuri WL, Santos RL, Arantes RM, Gonçalves R, de Melo MN, Michalick MS, et al. An alternative immunohistochemical method for detecting Leishmania amastigotes in paraffin-embedded canine tissues. J Immunol Methods. 2004;292(1-2):17-23.

23. Piarroux P, Azaiez R, Lossi AM, Reynier P, Muscatelli F, Gambarelli F, et al. Isolation and characterization of a repetitive DNA sequence from Leishmania infantum: development of a visceral leishmaniasis polymerase chain reaction. Am J Trop Med Hyg. 1993;49(3):364-9.

24. Laskay T, Diefenbach A, Rollinghoff M, Solbach W. Early parasite containment is decisive for resistance to Leishmania major infection. Eur J Immunol. 1995;25(8):2220-7.

25. Solano-Gallego L, Fernández-Bellon $\mathrm{H}$, Morell $\mathrm{P}$, Fondevila D, Alberola J, Ramis A, et al. Histological and immunohistochemical study of clinically normal skin of Leishmania infantum-infected dogs. J Comp Path. 2004;130(1):7-12.

26. Cochran WG, Cox GM. Experimental designs. 2nd ed. New York: John Wiley \& Sons; 1957.611 p.

27. Gradoni L. The diagnosis of canine leishmaniasis, moving towards a solution. In: Killick-Kendrick R, editor. Proceedings of the Second International Canine Leishmaniasis Forum, 2002. Sevilla, Spain; 2002. 7-14 p.

28. Bryden SL, White SD, Dunston SM, Burrows AK, Olivry T. Clinical, histopathological and immunological characteristics of exfoliative cutaneous lupus erythematosus in 25 German short-haired pointers. Vet Dermatol. 2005;16(4):239-52.

29. Almeida MAO, Jesus EEV, Sousa-Atta MLB, Alves LC, Berne MEA, Atta AM. Clinical and serological aspects of visceral leishmaniasis in Northeast Brazilian dogs naturally infected with Leishmania chagasi. Vet Parasitol. 2005;127(3-4):227-32.

30. Madeira MF, Figueiredo FB, Pinto AG, Nascimento LD, Furtado M, Mouta-Confort E, et al. Parasitological diagnosis of canine visceral leishmaniasis: is intact skin a good target? Res Vet Sci. 2009;87(2):260-2.
31. Travi BL, Tabares CJ, Cadena H, Ferro C, Osorio Y. Canine visceral leishmaniasis in Colombia: relationship between clinical and parasitological status and infectivity for sand flies. Am J Trop Med Hig. 2001;64(3-4):119-24.

32. Guarga JL, Moreno J, Lucientes J, Gracia MJ, Peribáñez MA, Alvar J, et al. Canine leishmaniasis transmission: higher infectivity amongst naturally infected dogs to sand flies is associated with lower proportions of $\mathrm{T}$ helper cells. Res Vet Sci. 2000;69(3):249-53.

33. Mozos E, Peréz J, Day MJ, Lucena R, Ginel PJ. Leishmaniosis and generalized dermodicoses in three dogs: a clinicopathological and immunohistochemical study. J Comp Pathol. 1999;120(3):257-68.

34. Tafuri WL, de Oliveira MR, Melo MN. Canine visceral leishmaniasis histopathological picture of one case reported from Brazil. Vet Parasitol. 2001;96(3):203-12.

35. dos-Santos WL, David J, Badaró R, de-Freitas LAR. Association between skin parasitism and granulomatous inflammatory pattern in canine visceral leishmaniasis. Parasitol Res. 2004;92(2):84-94.

36. Tarantino C, Rossi G, Kramer LH, Perucci S, Cringoli G, Macchioni G. Leishmania infantum and Neospora caninum simultaneous skin infection in a young dog in Italy. Vet Parasitol. 2001;102(1-2):77-83.

37. Bittencourt AL, Barral-Netto M. Leishmaniasis. In: Doerr W, Seifert G, editors. Tropical pathology. 2nd ed. New York/Berlin: Springer/Heidelberg; 1995. p. 597-651. 8 vol.

38. Rousseau D, Dermatino S, Ferrua B, Michiels JF, Anjuère F, Fragaki $\mathrm{K}$, et al. In vivo involvement of polymorphonuclear neutrophils in Leishmania infantum infection. BMC Microbiol. 2001;1(1):17.

39. Ribeiro-Gomes FL, Otero AC, Gomes NA, Moniz-deSousa MC, Cysne-Finkelstein L, Arnholdt AC, et al. Macrophage interactions with neutrophils regulate Leishmania major infection. J Immunol. 2004;172(7): 4454-62.

40. Aga E, Katschinski DM, van Zandbergen G, Laufs $\mathrm{H}$, Hansen B, Muller $\mathrm{K}$, et al. Inhibition of the spontaneous apoptosis of neutrophil granulocytes by the intracellular parasite Leishmania major. J Immunol. 2002;169(2):898-905.

41. de Freitas Balanco JM, Moreira ME, Bonomo A, Bozza PT, Amarante-Mendes G, Pirmez C, et al. Apoptotic mimicry by an obligate intracellular parasite downregulates macrophage microbicidal activity. Curr Biol. 2001;11(23):1870-3. 